\title{
As escolas técnicas do SUS: que projetos político-pedagógicos as sustentam?
}

\author{
| ${ }^{1}$ Ena de Araújo Galvão, ${ }^{2}$ Maria Fátima de Sousa |
}

Resumo: Esta pesquisa teve por objetivo explorar as visões político-pedagógicas expressas pelos gestores de cinco Escolas Técnicas do SUS (ETSUS), nas cinco regiōes do país. Procurou, ainda, compreender como essas instituições de ensino se organizam e se estruturam com vistas à sua sustentabilidade. O método centrouse na busca dos aspectos de natureza qualitativa. Os dados foram coletados a partir de um questionário (via e-mail) e dos seguintes documentos: atos de criação e de autorização, Projeto PolíticoPedagógico (PPP) e Regimento Escolar. O questionário semiestruturado foi dirigido às instituiçōes componentes da pesquisa para identificar sua sustentabilidade nas dimensões política, técnico-pedagógica e administrativo-financeira. A análise documental foi a técnica utilizada para organizar e armazenar os dados, seguida da análise de conteúdo, a partir das trilhas metodológicas propostas por Bardin (2007). Os resultados indicaram que houve flutuações nas diferentes dimensões, principalmente nos campos administrativo e financeiro, nos quais a fragilidade da governança dos gestores foi bastante acentuada. Outros resultados apontaram que a dimensão técnico-pedagógica, com sua proposta de PPP inovador, é efetivamente a que mais dá sustentabilidade às ETSUS, tornando-as diferentes das escolas do sistema formal de ensino, pela incorporação de princípios de gestão: descentralização curricular, processos administrativos centralizados e atuação multiprofissional no campo da saúde. Sua fortaleza pedagógica é traduzida principalmente pelo eixo metodológico de integração ensino-serviço, pela adequação do currículo ao contexto regional, utilização pedagógica dos espaços de trabalho, avaliação do desempenho dos alunos nos serviços com supervisão e acompanhamento pedagógico e pela docência exercida no campo de trabalho por profissional de nível superior qualificado pedagogicamente, tendo os princípios e diretrizes do SUS como norteadores dos planos de cursos. A dimensão política foi a que mais deu visibilidade ao trabalho da escola, propiciando-lhe, dessa forma, também, certa sustentabilidade. A formação/qualificação nos municípios trouxe benefícios aos alunos/trabalhadores e permitiu uma atuação mais próxima aos espaços descentralizados da gestão e da decisão. Analisaram-se, enfim, as dificuldades encontradas pelas escolas, onde há também necessidade de corrigir assimetrias nas dimensōes técnico-pedagógicas e administrativo-financeiras.

\author{
1 Pedagoga; mestre em Ciências \\ da Saúde pela Universidade de \\ Brasília.enagalvao@gmail.com. \\ 2 Enfermeira; professora \\ doutora do Departamento \\ de Saúde Coletiva, Faculdade \\ de Ciências da Saúde da \\ Universidade de Brasília. \\ fatimasousa@unb.br
}


As Escolas Técnicas do Sistema Único de Saúde (ETSUS) são instituições públicas criadas ou "recriadas" a partir de 1980 para qualificar/formar os trabalhadores de nível fundamental e médio empregados no SUS que não possuíam qualificação específica para as funções que desempenhavam. As primeiras ETSUS, criadas especialmente no âmbito do sistema de saúde, já tinham em seu Regimento Escolar as características de uma escola dessa natureza: eixo metodológico de integração ensino-serviço, adequação do currículo ao contexto regional, utilização pedagógica dos espaços de trabalho, avaliação do desempenho dos alunos nos serviços com supervisão e acompanhamento pedagógico e docência exercida por profissional de nível superior dos serviços, qualificado pedagogicamente, tendo os princípios e diretrizes do SUS como norteadores dos planos de cursos.

Hoje, há um total de 36 escolas constituídas em rede (RETSUS) pela Portaria $\mathrm{n}^{\circ} 2.970$, de 25 de novembro de 2009. A coordenação dessa rede está a cargo da Secretaria de Gestão do Trabalho e da Educação em Saúde (SGTES), do Ministério da Saúde.

No início, foi difícil convencer os gestores da saúde da necessidade de criação de escolas dessa natureza. Assim, houve oportunidade de escolas já em funcionamento ou desativadas ingressarem na rede. No caso desta pesquisa, duas escolas de auxiliares de enfermagem do sistema de ensino estavam desativadas e foram "recriadas" a partir da aprovação de novo regimento e da incorporação das características inerentes a uma ETSUS.

Para atender a essa necessidade, as ETSUS foram criadas num contexto de redemocratização da sociedade brasileira, como estratégia frente aos problemas, já identificados naquela época, da baixa qualificação da força de trabalho empregada nos serviços de saúde e da necessidade de se articularem o setor saúde e o setor educação.

Segundo Sório e Lamarca (1998, p. 147),

as Escolas Técnicas de Saúde do SUS, no Brasil, são entidades governamentais que foram criadas para exercer papel estratégico na promoção da profissionalização dos trabalhadores de nível médio, sem qualificação específica, para o desenvolvimento das açôes de saúde. Às Escolas Técnicas de Saúde é atribuído, pois, o papel fundamental de proposição e implementação da política de educação para o SUS, tanto do ordenamento da formação dos profissionais de saúde, como na adequação dos perfis profissionais e educação permanente dos trabalhadores. 
O trabalho dessas instituições de ensino é focado na formação de recursos humanos de nível médio para o setor saúde, tomando as práticas em saúde como referência. Isso significa incorporar ao processo educativo as necessidades de saúde e o perfil epidemiológico da população como produção da doença e da saúde.

$\mathrm{O}$ fenômeno em estudo neste artigo (visões político-pedagógicas e seus reflexos na sustentabilidade das ETSUS) não é algo comum dentro de uma instituição de educação profissional e não possui vasta literatura a seu respeito, pelas especificidades das próprias escolas do SUS. Começam a aparecer, na última década, dissertações e artigos produzidos principalmente pelos gestores e docentes dessas instituições, abordando aspectos pedagógicos referentes ao desenvolvimento dos diferentes cursos, ou, ainda, apontando necessidades de aprofundamento de estudos desse modelo de escola.

A primeira etapa deste estudo buscou compreender o contexto sócio-histórico em que surgem as ETSUS, num recorte temporal que contemplou o final da década de 70 e início dos anos 80, quando o Programa de Extensão de Cobertura (PEC) trouxe como marco importante a incorporação de grupos populacionais carentes para atendimento nos serviços de saúde e, com ela, a incorporação de pessoas de nível auxiliar, recrutadas na comunidade. Para a preparação desse contingente a ser incorporado à força de trabalho em saúde, foi criado o Programa de Preparação Estratégica de Pessoal de Saúde (PPREPS) que punha em destaque uma política de recursos humanos mais estruturada, coerente com o II Plano Nacional de Desenvolvimento (PND 1974-1979). O PPREPS buscou reformular as práticas de gestão e de capacitação por meio de seus três objetivos: (1) preparação massiva de pessoal de nível médio e elementar, (2) constituição de 10 regiōes docentes assistenciais de saúde (Projetos Integração Docente-Assistencial/PIDA) e (3) estabelecimento de uma base operacional nos estados, os órgãos ou núcleos de recursos humanos como instâncias estaduais para condução descentralizada das políticas e programas nessa área. (RAMOS; PEREIRA, 2006).

Apesar da incorporação de um número expressivo de pessoas com o PPREPS, um estudo da força de trabalho em saúde realizado no final da década de 70 por Nogueira (1983) indica que 300 mil trabalhadores empregados exerciam funções sem a qualificação específica. É assim, no âmbito do PPREPS, que se inicia o debate sobre a formação dos trabalhadores em saúde, com vistas a superar as propostas educativas baseadas em treinamento. É nesse cenário também que surge 
e se expande o Projeto de Formação de Pessoal de Nível Médio e Elementar para a Saúde, o Projeto Larga Escala (PLE). O projeto, portador de intencionalidade social e histórica, objetivava melhorar a qualidade da atenção por meio da qualificação dos trabalhadores e de processos formativos desenvolvidos a partir de currículos autorizados pelo sistema de ensino. Possibilitava-se, dessa forma, a certificação dos concluintes e até mesmo o direito de concorrerem a outros empregos.

Rodrigues (2009) avalia a importância desse projeto ao afirmar que

Compreender o surgimento do PLE e sua base conceitual no campo da educação na área da saúde nos anos de 1980 implica considerar [...] os segmentos desfavorecidos economicamente, $[\ldots]$ que não tinham acesso aos serviços de saúde e, $[. .$.$] por outro$ lado, na linha da prestação dos serviços de saúde, reconhecer um contingente de trabalhadores, na sua maioria de nível médio e elementar, desprovida de qualificação específica [...]. Além desses antecedentes, é preciso entender o caráter da inclusão a partir da identidade profissional, discurso do PLE, conferindo legitimidade profissional, proporcionando ascensão social e profissional ao trabalhador, resgatando uma dívida social para com ele (p. 40).

Ainda nas décadas de 80 e 90, o processo de municipalização trouxe inovações para o SUS, ressaltando a expansão dos setores público e privado, que absorveram mais de 2 milhões de empregados (MACHADO, 2006), o que obrigou o poder público a criar instâncias de formação para a preparação dessa força de trabalho que ingressava no sistema. É nesse período que surgem as ETSUS, com a responsabilidade de formação de um profissional técnico de nível médio, considerando não apenas os requisitos legais do sistema de ensino, mas, sobretudo, os debates que ocorriam dentro do setor saúde, com vistas a subsidiar a luta política para incorporação de princípios e direitos na nova Carta Magna, em discussão pela sociedade brasileira.

Para Leão (2009, p. 13),

a complexidade do conceito de saúde, definido na $8^{\text {a }}$ Conferência Nacional de Saúde (1986) e legitimado na Constituição Federal de 1988, requer para sua operacionalização profissionais formados sob uma ótica ampla, capazes de levar em conta a dimensão política, social, cultural, técnica e biológica de seu objeto, o que implica a adoção de uma educação que apoie a formação de trabalhadores em saúde a fim de reorientar suas práticas.

Nesse cenário de articulações e confrontos em que são criadas as ETSUS, com vinculações múltiplas em relação às mantenedoras, buscou-se compreender os projetos político-pedagógicos que as sustentavam. A sustentabilidade, para fins 
deste estudo, é entendida como a garantia de condições mínimas de natureza política, pedagógica, administrativa e financeira por parte das mantenedoras, de forma a assegurar o funcionamento da ETSUS e propiciar o alcance de sua missão. A divisão em três dimensões é didática, apenas para facilitar a análise, uma vez que elas podem apresentar-se de forma concomitante.

\section{Perfil das cinco Escolas Técnicas do SUS}

\section{E1 - Região Norte}

O estado cuja escola foi selecionada está situado a sudoeste da região Norte do Brasil e seu território é composto por $90 \%$ de floresta, grande patrimônio do seu povo. O local convive com doenças da pobreza e do desenvolvimento, destacandose doenças endêmicas, de veiculação hídrica, além das doenças crônicas. Diante desse quadro epidemiológico, o Estado decidiu qualificar, por meio da ETSUS, os trabalhadores do SUS nas diferentes áreas para ações de promoção, prevenção e recuperação da saúde.

A escola é originária da antiga Escola Estadual de Enfermagem, criada pelo Decreto Estadual no 51, de 13 de novembro de 1964, vinculada à Secretaria Estadual de Saúde. Ela funcionou em espaços físicos cedidos, como o Hospital da Fundação do Estado, e foi diversas vezes desativada.

Em dezembro de 2001, foi "recriada" de forma estratégica e localizada no Departamento de Educação Profissional da Secretaria de Educação (Decreto n ${ }^{\circ}$ 4.577, de 2001) para viabilizar a formação dos auxiliares e técnicos de enfermagem do Programa de Formação dos Trabalhadores da Área da Enfermagem (PROFAE). Com uma gestão compartilhada com a Secretaria de Estado da Saúde, a escola está administrativamente vinculada a um Instituto Estadual de Desenvolvimento da Educação Profissional, fundação estadual mantenedora da instituição.

Ainda que possua uma sede própria, inaugurada em setembro de 2006, a escola oferece também cursos descentralizados nos municípios onde haja necessidade de formação e qualificação.

\section{E2 - Região Nordeste}

A E2 foi criada em $1^{\circ}$ de fevereiro de 1984 pelo Decreto no 8.861 do Governo do Estado especialmente para ser uma ETSUS. A partir de 1986, o Decreto de 
no 9.481 , de 13 de fevereiro de 1986, altera seu nome, que passa a ser o de um médico do estado. Integrando a estrutura da Secretaria Estadual de Saúde, a escola é subordinada administrativamente ao secretário de Estado.

Em 1999, com a implantação do PROFAE, a escola desencadeou um processo de reorganização administrativa e pedagógica para atuar de forma mais eficiente no SUS e responder às exigências impostas pelo cenário econômico e social e pelos princípios da educação profissional. Assim, foram incorporados dois órgãos colegiados: o Conselho Escolar e o Conselho de Classe. O primeiro tem a função geradora de descentralização dos processos decisórios; já o segundo se volta para decisões na área pedagógica.

Os cursos oferecidos estão vinculados ao eixo tecnológico (Ambiente, Saúde e Segurança) e são oferecidos seja de forma centralizada na escola, seja de forma descentralizada nas sedes das Unidades Regionais de Saúde, ou ainda em parceria com as Secretarias Municipais de Saúde.

Para ter acesso aos cursos é necessário ser trabalhador do SUS e, em caráter excepcional, ser oriundo da comunidade.

\section{E3 - Regiáo Centro-Oeste}

A E3 teve sua origem na década de 80 , atuando inicialmente na qualificação da força de trabalho para atender aos serviços de saúde frente às grandes dificuldades enfrentadas devido à falta de mão de obra qualificada. Por não possuir autorização do sistema educacional para certificar os alunos, seu início se deu em parceria com uma escola estadual de $1^{\circ}$ e $2^{\circ}$ graus do sistema de ensino.

A construção de um hospital regional em um dos municípios do estado foi fator determinante para a criação da ETSUS em 1992, pois a região não possuía pessoal qualificado em número suficiente para ser incorporado ao serviço de saúde.

Em setembro de 1992, a E3 passa a integrar a estrutura organizacional da Secretaria Estadual de Saúde (SES) como órgão de execução programática da política de Recursos Humanos do SUS. A Lei no 7.236, de 1999, reorganiza a estrutura da Secretaria de Estado da Saúde, e a escola técnica passa a ser um Núcleo de Formação Técnica em Saúde (NFTS) da Coordenadoria de Recursos Humanos.

Em abril de 2001, foi criada a Escola de Saúde Pública (ESP) para ofertar programas de educação continuada e permanente aos profissionais 
de nível superior, oferecendo cursos de especialização (em parceria com uma universidade). A ETSUS foi extinta em janeiro de 2000. Dois anos depois, a ESP foi credenciada pelo Conselho Estadual de Educação para ministrar os cursos de educação profissional de nível técnico na área de Saúde.

A direção da escola conta com uma equipe de profissionais que desenvolvem funções específicas junto aos diferentes setores. Esses profissionais, inclusive os docentes, são credenciados, via edital, para prestar serviços na escola.

Atualmente, a ESP possui autonomia didático-pedagógica, administrativa, orçamentária e financeira conferida pelo Decreto $\mathrm{n}^{\circ} 1.816$, de 05 de fevereiro de 2009. O diretor é eleito pela comunidade escolar e a escola tem assento no Conselho Estadual de Educação.

\section{E4 - Região Sudeste}

Para cumprir suas finalidades, a E4 realizou, em 1991, uma pesquisa sobre a força de trabalho de níveis médio e fundamental existente no estado, inserida nos serviços de saúde públicos e privados, ambulatoriais e hospitalares. Após análise dos dados obtidos, consulta à literatura especializada, revisão da legislação em vigor e discussão do tema com especialistas da área, optou-se pela criação de uma escola específica para o setor saúde, frente ao vazio de instituições de ensino dessa natureza ligadas ao SUS.

Foi instituído de forma orgânica na estrutura da universidade o Centro de Ensino Médio e Fundamental para abrigar a Escola Técnica de Saúde, que teve sua autorização de funcionamento em 1993.

A criação da E4 deu-se em um contexto de transição da instituição privada de ensino para autarquia pública. $\mathrm{O}$ mecanismo de custeio da nova escola, à época, foi a remuneração dos serviços educacionais pelos empregadores, que aos poucos foram repassando o custo para o aluno empregado. Com a consolidação da universidade pública estadual e a realização de estudos, análises, discussões e reflexões, foi possível oferecer ensino gratuito aos trabalhadores.

Novos estudos e levantamentos a partir de 1999 possibilitaram ao centro de ensino a oferta de cursos para além da área da saúde. No campo do comércio, foi criado o curso de qualificação em administração para atender às necessidades da Câmara de Dirigentes Lojistas. A E4 abriga, ainda, uma estação de pesquisa que 
vem acompanhando os egressos da escola, promovendo trocas de experiências com outras estaçōes e oferecendo dados e informaçōes sobre educação profissional de nível médio em saúde e necessidades do sistema de saúde e do mundo do trabalho. Hoje, ela participa da Rede Observatório de Recursos Humanos em Saúde, composta por um conjunto de instituições de pesquisa e assistência.

Verificando a necessidade de preparação dos docentes e gozando do privilégio de estar inserida numa universidade, a E4 propõe um curso de especialização para a formação docente. Para consolidar as ações da universidade no interior do estado, a escola descentraliza o curso de forma a atender aos docentes dos municípios e, dessa forma, apoiar a oferta de uma educação pública de qualidade.

\section{E5 - Região Sul}

A E5 é atualmente vinculada a uma Secretaria Municipal de Saúde. Em março de 1953, em relatório apresentado à Câmara de Vereadores, a Comissão de Construção do Hospital Santo Antônio do Município incluiu no seu plano de obras a construção de instalaçóes para o funcionamento de uma futura escola de auxiliares de enfermagem.

Em 1956, a escola é criada, pela Lei no 763 , anexa ao Hospital Municipal Santo Antônio, funcionando em local especialmente construído na nova ala do hospital, sendo o primeiro curso de auxiliares de enfermagem do estado. Ela funcionaria de acordo com a Lei $\mathrm{n}^{\circ} 70$, de 06 de agosto de 1949, que regulava o ensino de enfermagem no país. Seu diretor seria obrigatoriamente diplomado em enfermagem, de preferência com uma especialização. $O$ poder executivo municipal ficava autorizado a contratar professores e serviços das pessoas que se fizessem necessários. As despesas decorrentes da Lei correriam pela verba 3 - da Educação Pública, da Lei Orçamentária do Município.

Em 1968, a Fundação Universidade Regional (FURB) incorporou ao seu patrimônio a Escola de Auxiliar de Enfermagem. Em 1979, esta passa a integrar as estruturas da Secretaria Municipal de Educação, onde permaneceu até julho de 1996. Até 1992, a escola oferecia apenas curso de formação de auxiliar de enfermagem.

Em 1996, por Lei Complementar, a escola passa a integrar as estruturas da Secretaria Municipal de Saúde (SEMUS). Nesse período, ela é "recriada” a partir 
da alteração de seu regimento, da diversificação de cursos para outras áreas, da

oferta de cursos descentralizados, da incorporação de metodologias ativas que propiciassem a integração ensino-serviço, da caracterização da docência como função e de outras questôes consideradas importantes para que a escola pudesse atender às necessidades do SUS na formação de RH no estado.

Em 1997, foi oficializada a alteração de seu nome, agora Escola Técnica de Saúde (ETS).

\section{Metodologia}

Para a realização deste estudo, optou-se pela abordagem qualitativa, considerada mais apropriada por permitir explorar questôes "não muito postas" que poderiam ajudar a pensar caminhos políticos, técnico-pedagógicos e administrativofinanceiros para as demais escolas da RETSUS. Essa escolha é corroborada por Cerqueira (2011, p. 29), que afirma:

Quando se trata de fenômenos naturais, o estudo tem a primazia das ferramentas da análise estatística, sendo a frequência das ocorrências e a associação entre elas as chaves de sustentação das conclusões. No entanto, quando o objeto analisado pertence ao campo das ciências sociais, sua compreensão demanda o desenvolvimento de um conjunto de relações que geram os sentidos que os justifica, o que torna as ferramentas estatísticas secundárias, por se tratar de outro nível de objetividade.

Neste estudo, buscou-se estudar os projetos político-pedagógicos que dão sustentabilidade às cinco ETSUS, selecionadas a partir de dois critérios de inclusão: abranger-se-ia uma ETSUS por região geográfica e cada uma delas deveria ter vinculação administrativa/mantenedora diferenciada das outras. A escolha por região foi aleatória. Já a escolha por mantenedora partiu da hipótese de que a vinculação administrativa era determinante para a sustentabilidade das ETSUS.

A coleta dos dados foi realizada em setembro e outubro de 2011, em quatro tipos de documentos oficiais (ato de criação, ato de autorização, regimento escolar e Projeto Político-Pedagógico). Cada um dos documentos foi codificado, identificando a sigla da regiāo a que cada escola pertence. Elas ficaram assim denominadas:

E1 - Escola da Região Norte - Mantenedora: Secretaria Estadual de Educação;

E2 - Escola da Regiāo Nordeste - Mantenedora: Secretaria Estadual de Saúde; 
1168 E3 - Escola da Região Centro-Oeste - Mantenedora: Escola de Saúde Pública;

E4 - Escola da Região Sudeste - Mantenedora: Universidade Estadual;

E5 - Escola da Região Sul - Mantenedora: Secretaria Municipal de Saúde.

Codificadas as escolas e seus respectivos documentos, foram organizadas pastas eletrônicas para a armazená-los, de modo a facilitar a análise documental. Os documentos de cada ETSUS são oficiais. Sua razão de escolha foi sua constituição como arcabouço legal da escola e o fato de possibilitarem o estudo das motivações, atitudes, valores, crenças e tendências que manifestavam. Eles foram codificados para manter o sigilo das informações fornecidas por cada escola. Também foi aplicado a cada uma das cinco ETSUS, em outubro de 2011, um questionário semiestruturado, encaminhado aos gestores via e-mail. As respostas também passaram pelo mesmo processo de codificação para o posterior arquivamento na pasta eletrônica da respectiva escola.

Todos os documentos foram fichados num instrumento criado pelas pesquisadoras, o qual contava com um resumo e algumas informações consideradas relevantes para identificar aspectos da sustentabilidade das escolas nas dimensões pretendidas.

Dos questionários, também foram sintetizadas as informações por blocos que consideraram:

- perfil do sujeito (idade, sexo, formação, tempo na gestão, forma de escolha para o cargo);

- perfil da escola: ano de criação, atividades que realiza, aspectos técnico-pedagógicos (cursos oferecidos nas diferentes modalidades e sua descentralização, corpo docente e discente, demandas, produção científica, monitoramento das ações); aspectos políticos (vinculação, nível de participação dos atores nas ações da escola autonomia e flexibilidade e as necessidades decorrentes, nível e dificuldades na execução das atividades); aspectos administrativo-financeiros (organização e informatização do setor meio, procedimentos que realiza e nível de dificuldades, orçamento próprio, suprimento das necessidades e avaliação da escola por órgão externos);

- facilidades e dificuldades de natureza política, técnico-pedagógica e administrativo-financeiras 
Documentos e questionários serviram de suporte mútuo para o refinamento da análise dos dados e permitiram um olhar para cada uma das dimensões propostas para o estudo e a compreensão das condições objetivas no cenário em que cada uma delas existe e se desenvolve.

Com os registros efetuados na etapa da análise documental, iniciou-se a análise de conteúdo, seguindo as trilhas metodológicas propostas por Bardin (2007). Estudaram-se os textos selecionados, identificando sua inserção num contexto social mais amplo e procurando desvelar seus aspectos de sustentabilidade nos âmbitos político, técnico-pedagógico e administrativo-financeiro.

Definimos como categorias a serem analisadas as três dimensões: política, técnico-pedagógica e administrativo-financeira. Foram eleitas no texto Unidades de Registro (UR), definidas por Bardin (2007) como a "unidade de significação a codificar e correspondente ao segmento de conteúdo a considerar como unidade de base, visando à categorização e à contagem frequencial”. As palavras selecionadas como UR e analisadas no âmbito dos documentos oficiais e nas respostas ao questionário foram:

- Na dimensão política: vinculação, articulação/parcerias, descentralização, valorização do magistério e gestão democrática;

- Na dimensão pedagógica: organização curricular, integração ensino-serviço, metodologia e avaliação;

- Na dimensão administrativo-financeira: orçamento próprio, captação de recursos, autonomia, informatização do setor.

Com as considerações das leituras ou por inferência e com base nos objetivos da pesquisa, identificamos alguns resultados que, se não são definitivos, apontam possibilidades de aprofundamento em outros estudos.

\section{Resultados e discussões}

Do ponto de vista da legalização, todas as escolas foram criadas e autorizadas pelos respectivos sistemas de ensino, conforme atos normativos analisados. A E1 e a E3 foram desativadas, mas já tiveram seus atos revalidados.

Nas três dimensões estudadas, são estes os resultados: 


\begin{tabular}{|c|c|c|c|c|c|}
\hline \multirow{5}{*}{ 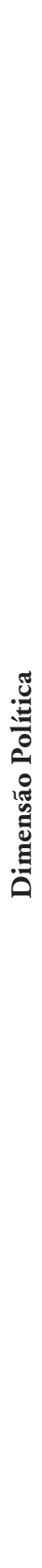 } & 诖 & 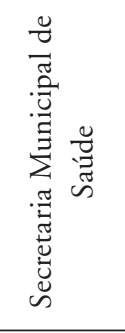 & 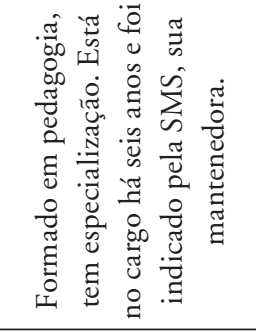 & 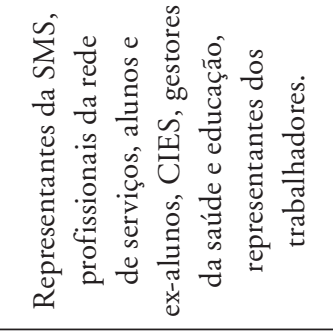 & 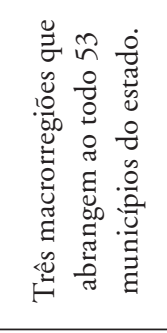 \\
\hline & 式 & 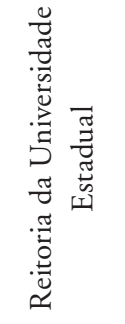 & 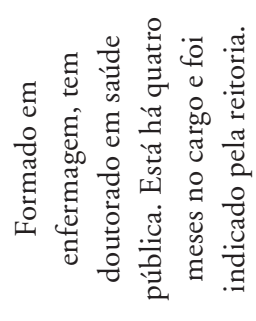 & 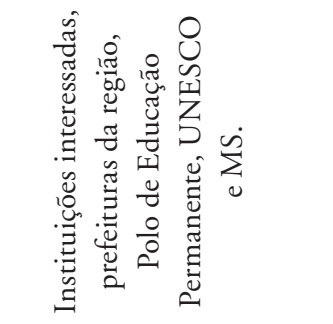 & 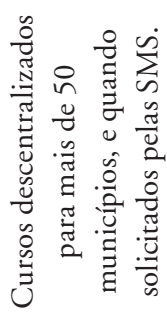 \\
\hline & $\stackrel{n}{\omega}$ & 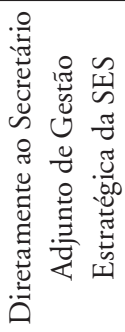 & 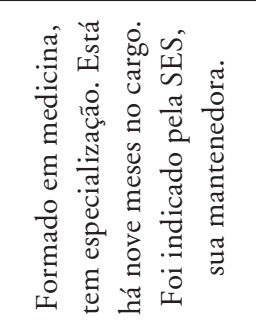 & 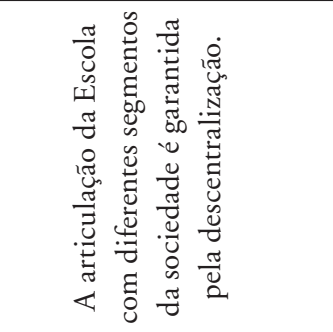 & 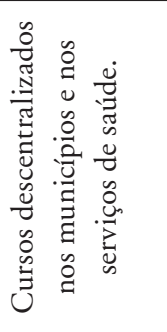 \\
\hline & 岑 & 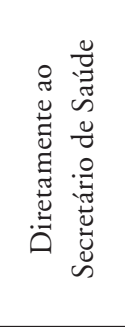 & 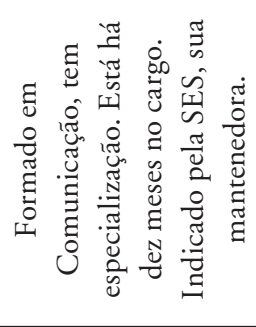 & 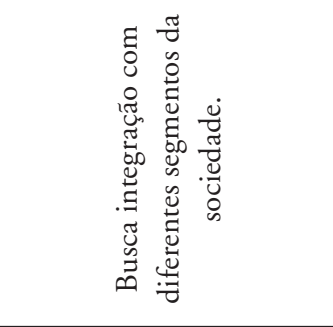 & 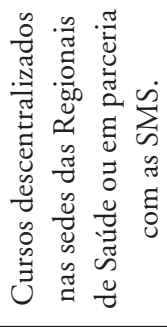 \\
\hline & 푀 & 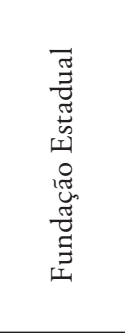 & 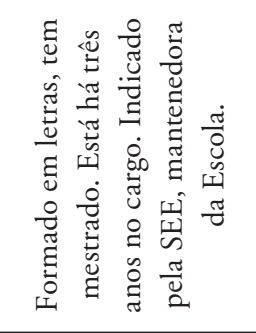 & 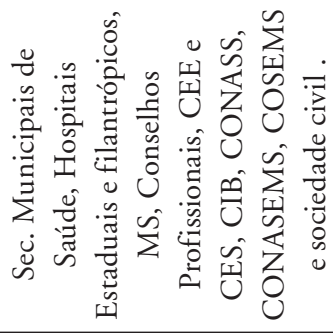 & 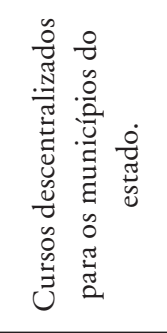 \\
\hline & & 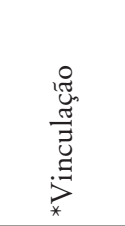 & 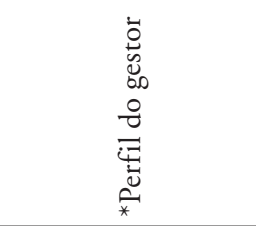 & 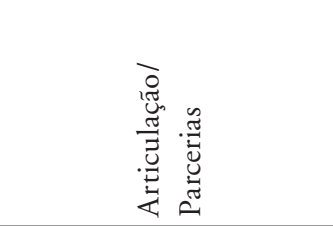 & 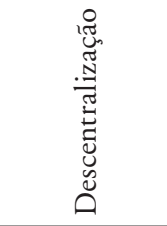 \\
\hline
\end{tabular}




\begin{tabular}{|c|c|c|c|c|}
\hline \multirow{5}{*}{ 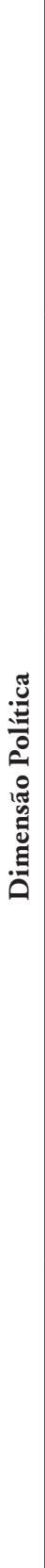 } & 杄 & 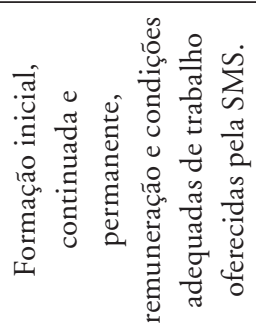 & 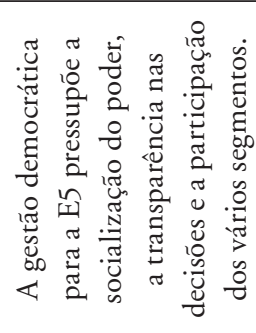 & 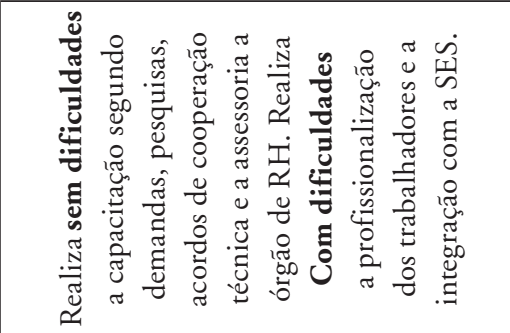 \\
\hline & 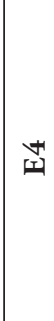 & 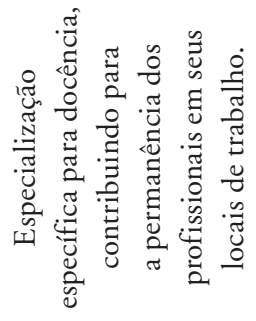 & 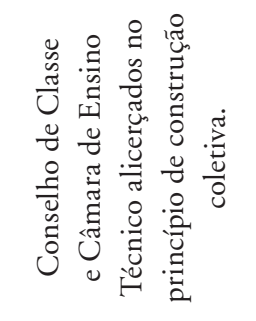 & 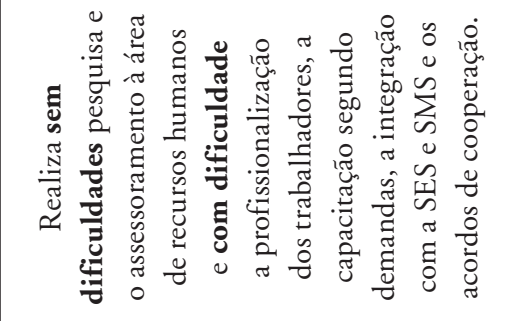 \\
\hline & 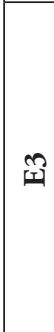 & 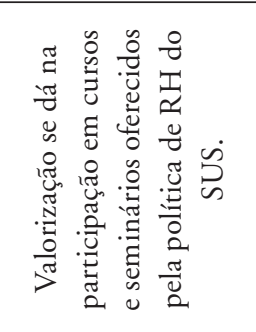 & 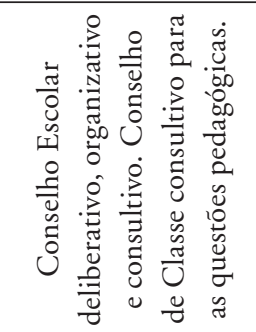 & 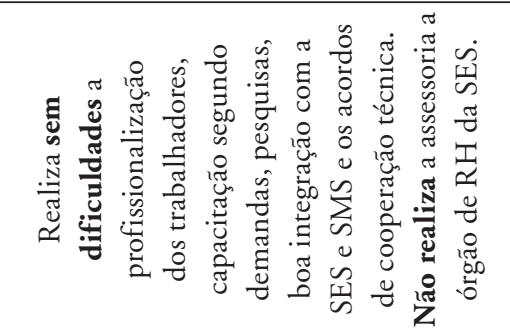 \\
\hline & $\widetilde{\sim}$ & 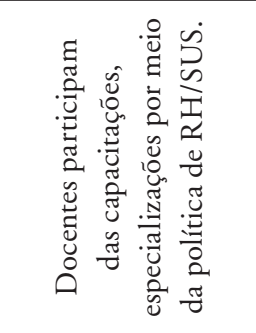 & 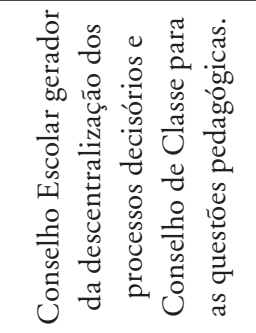 & 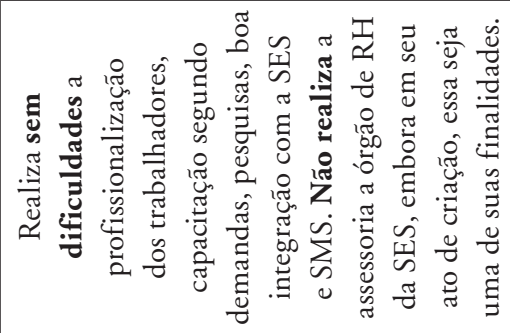 \\
\hline & 弐 & 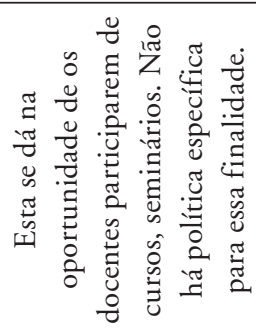 & 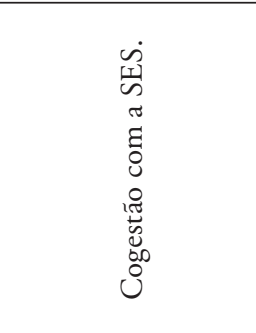 & 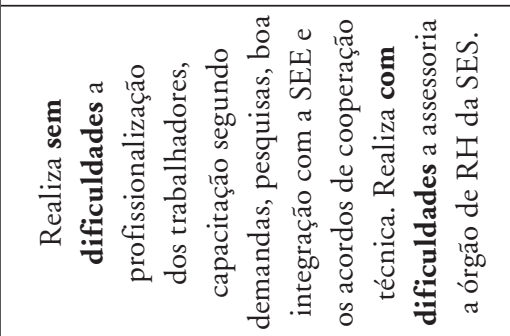 \\
\hline & 光 & 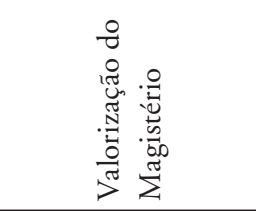 & 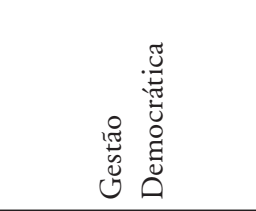 & 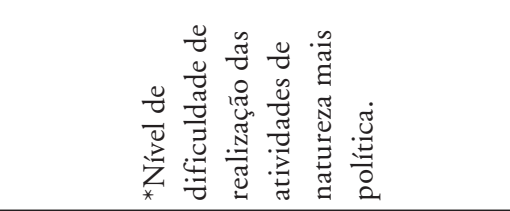 \\
\hline
\end{tabular}




\begin{tabular}{|c|c|c|c|}
\hline \multirow{5}{*}{ 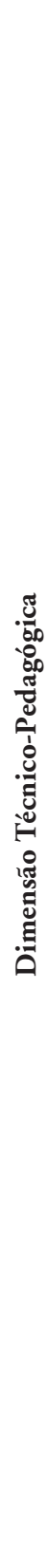 } & 诖 & 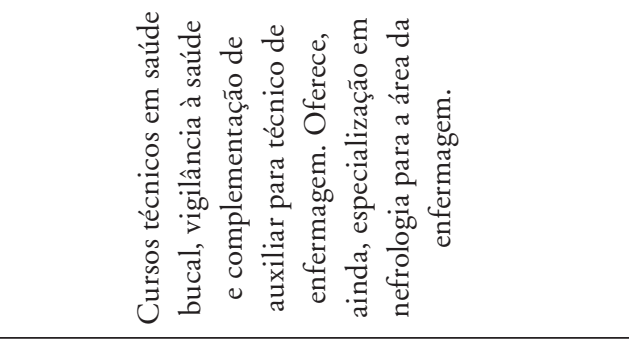 & 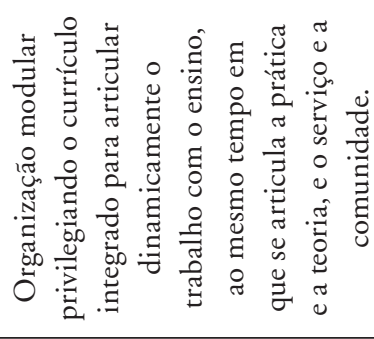 \\
\hline & $\stackrel{+1}{w}$ & 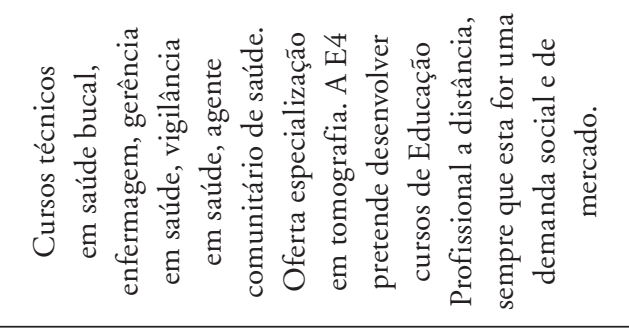 & 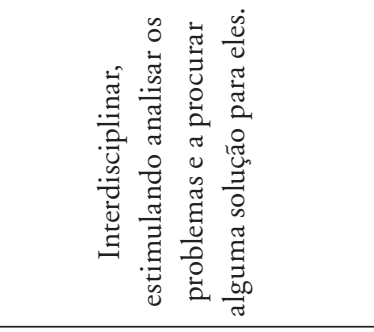 \\
\hline & 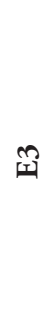 & 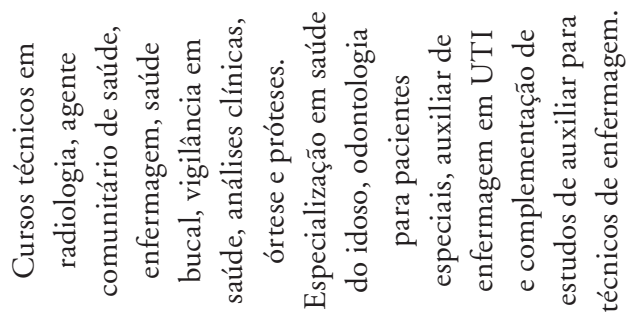 & 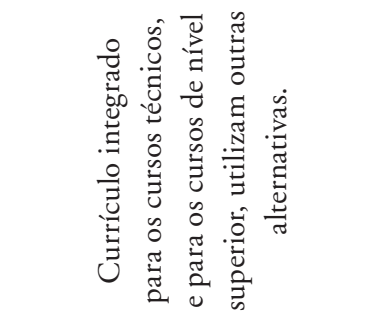 \\
\hline & $\widetilde{N}$ & 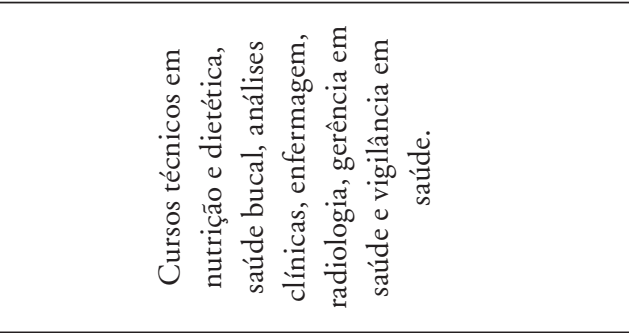 & 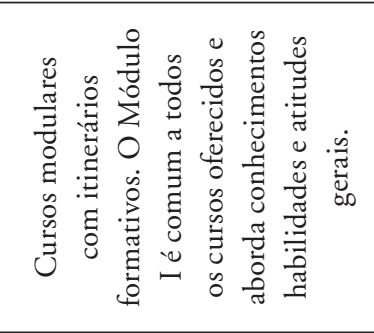 \\
\hline & 포 & 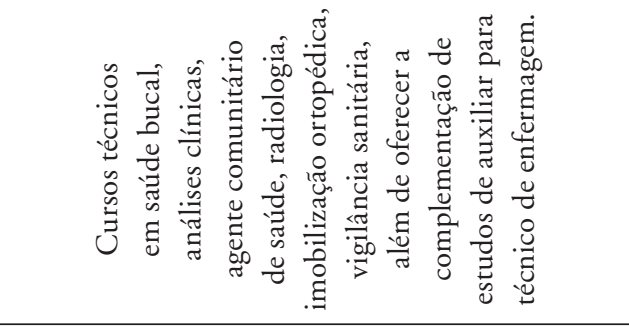 & 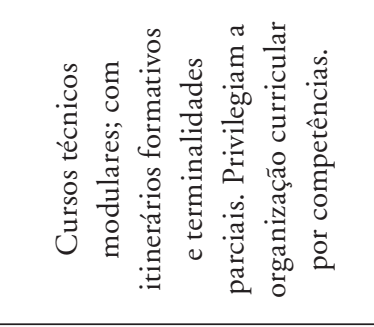 \\
\hline 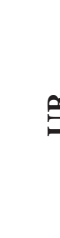 & & 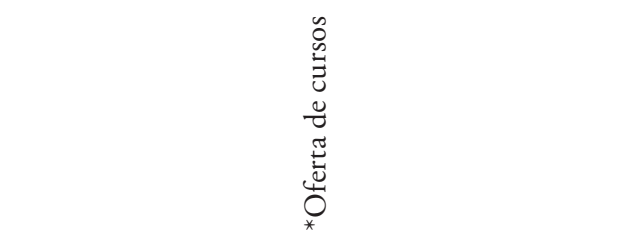 & 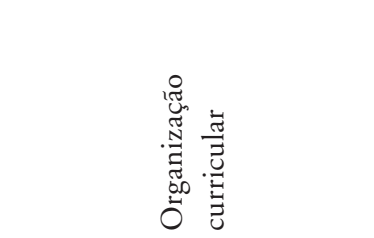 \\
\hline
\end{tabular}




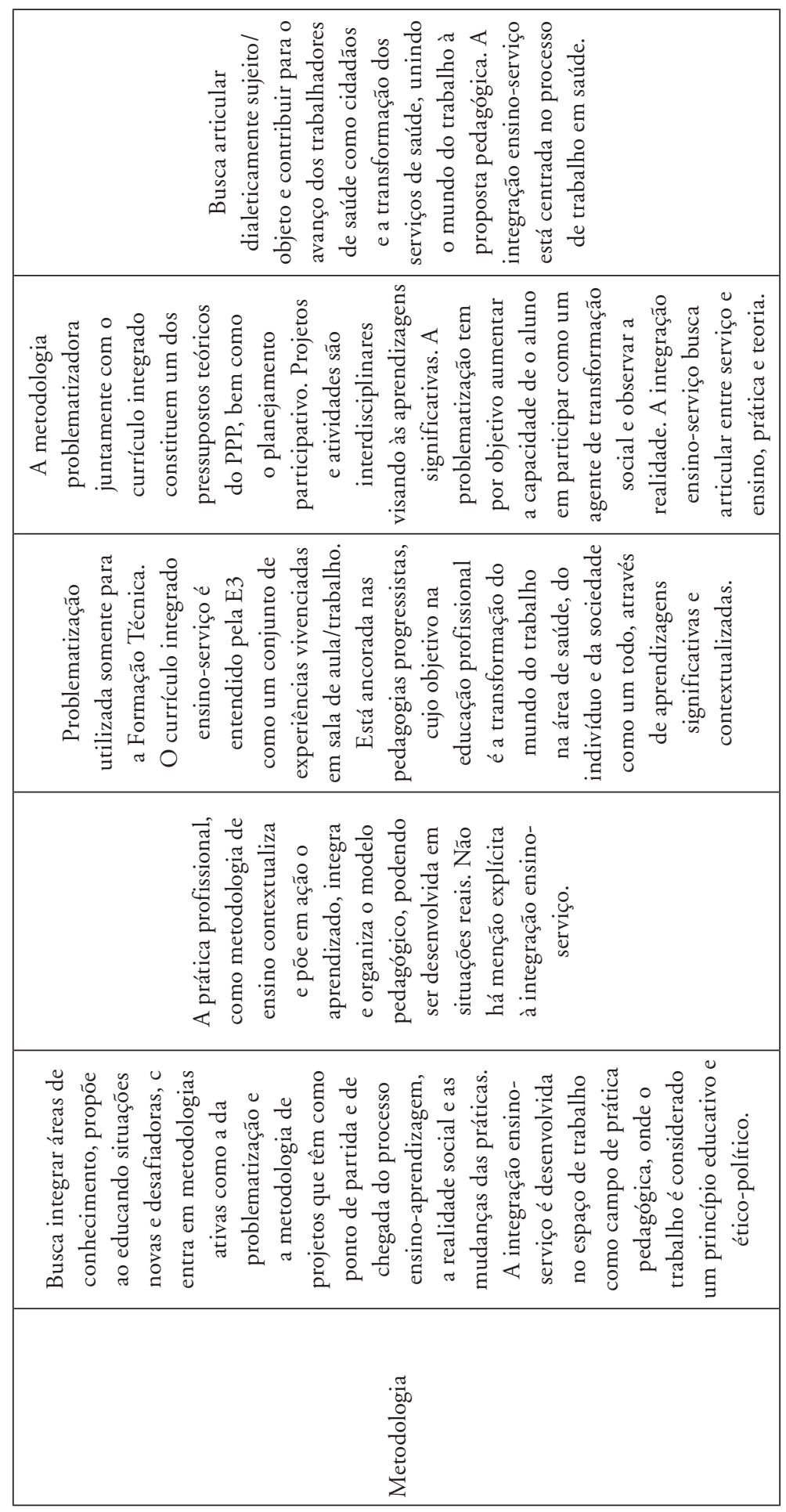




\begin{tabular}{|c|c|c|c|}
\hline \multirow{5}{*}{ 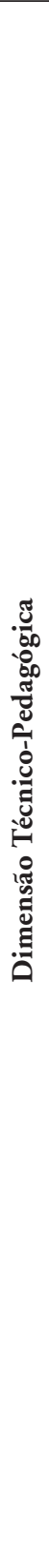 } & n & 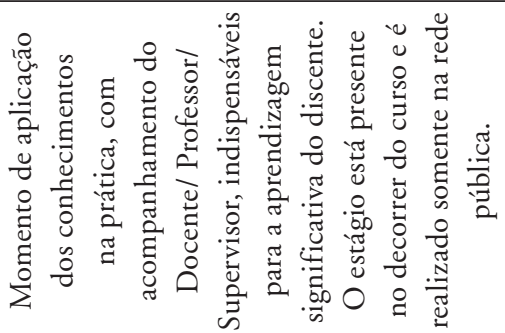 & 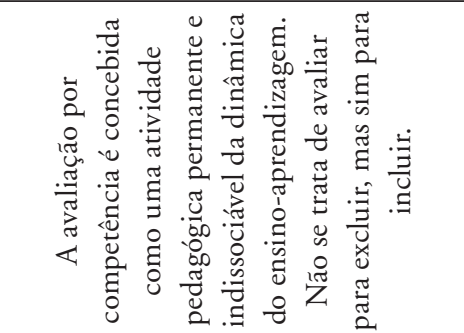 \\
\hline & $\stackrel{W}{w}$ & 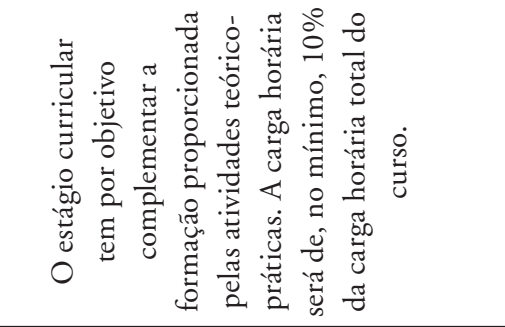 & 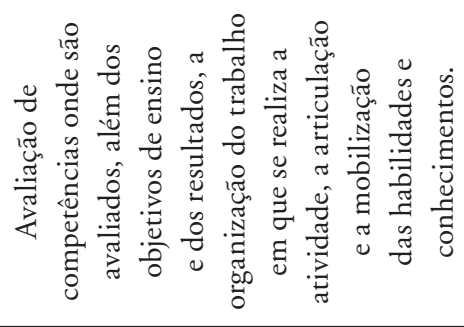 \\
\hline & $\underline{m}$ & 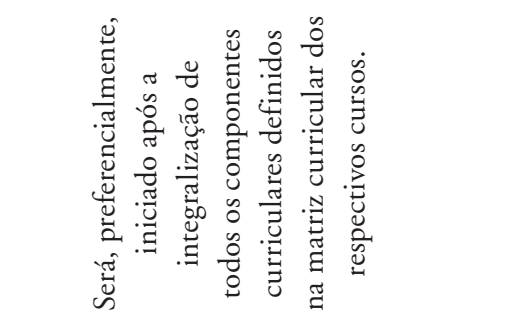 & 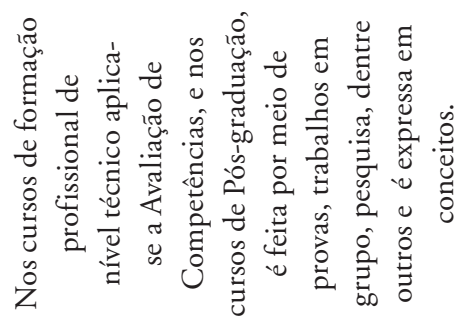 \\
\hline & $\widetilde{N}$ & 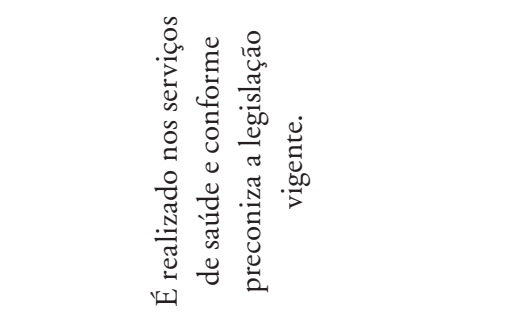 & 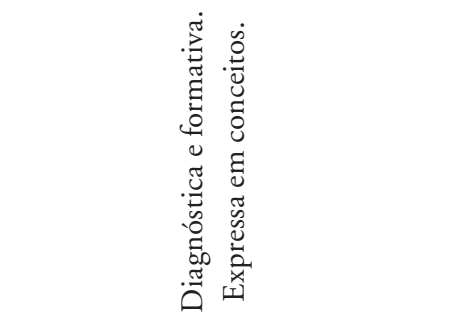 \\
\hline & 포 & 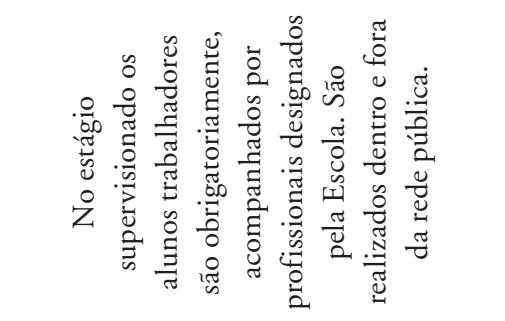 & 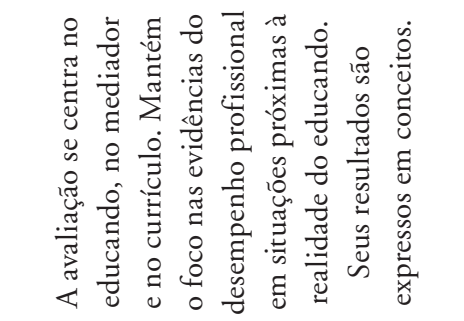 \\
\hline & & 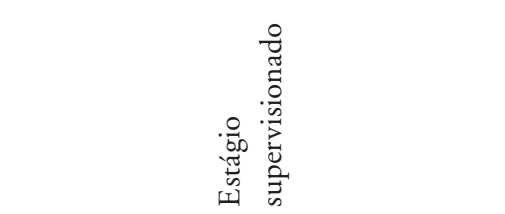 & 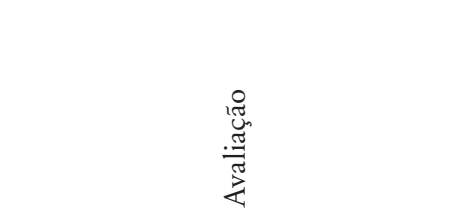 \\
\hline
\end{tabular}




\begin{tabular}{|c|c|}
\hline 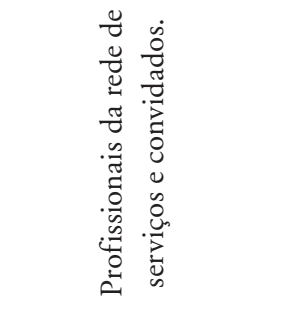 & 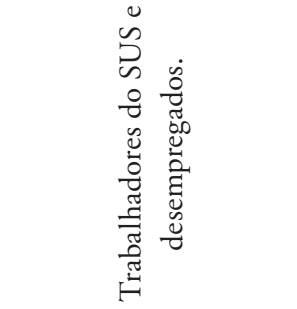 \\
\hline 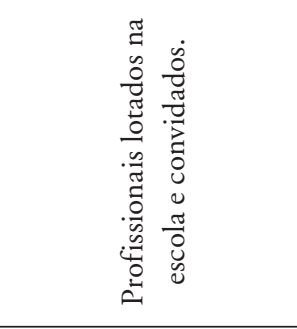 & 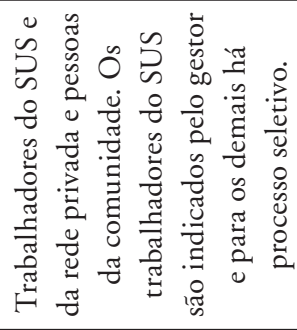 \\
\hline 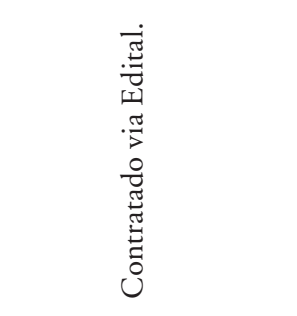 & 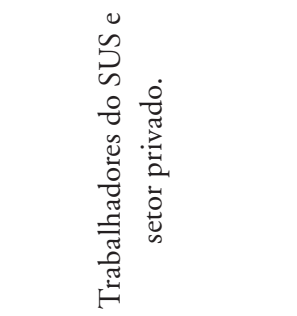 \\
\hline 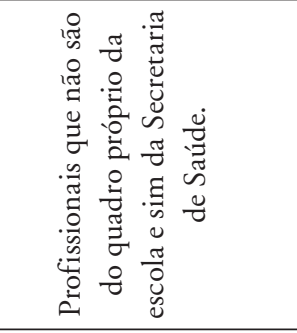 & 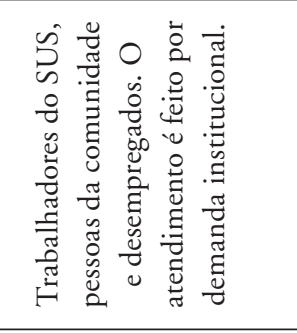 \\
\hline 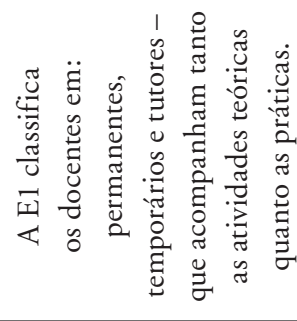 & 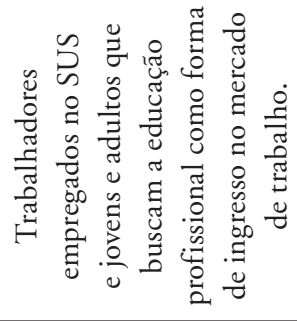 \\
\hline 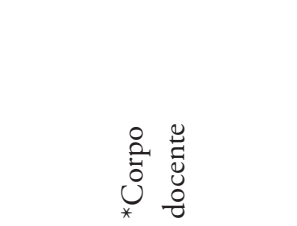 & 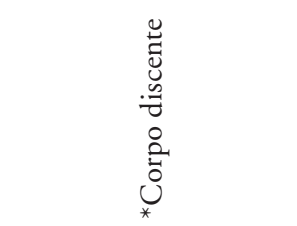 \\
\hline
\end{tabular}




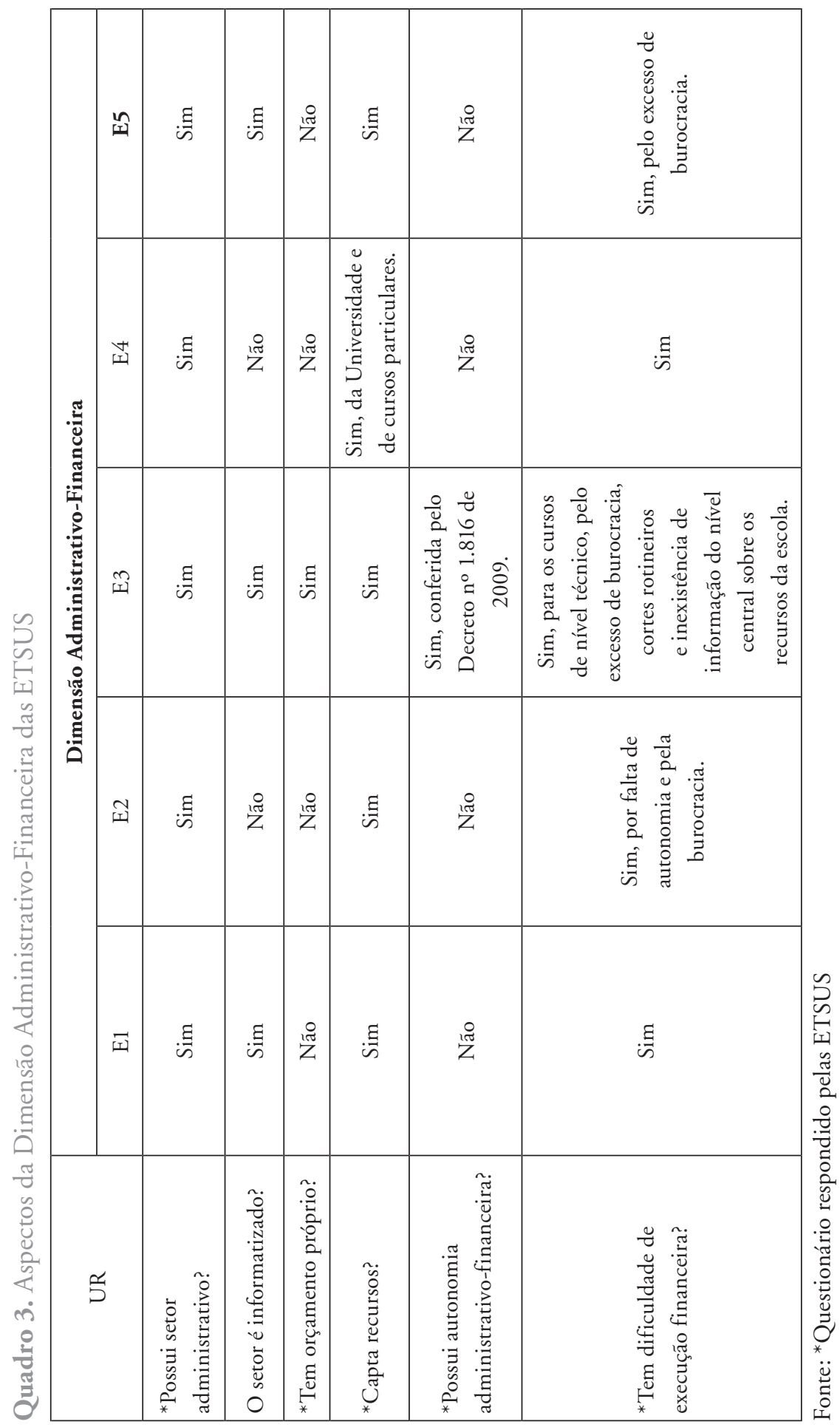


Em relação à vinculação com as mantenedoras, a E2 e E3 afirmaram no questionário que, mesmo estando em vinculação direta com o Secretário de Saúde, têm dificuldade de acesso às decisōes fora de seu âmbito de poder.

No que se refere à descentralização, foi constatado pelos PPP que todas as escolas oferecem cursos nos municípios à medida que são demandados pelos gestores e que são organizadas as condições para a execução das atividades educativas. O componente curricular descentralizado foi autorizado pelos Conselhos de Educação de cada estado, o que é comprovado no regimento escolar.

A valorização do magistério é identificada no PPP por conta do oferecimento de oportunidades de participação em cursos, seminários e outros eventos de natureza pedagógica. Com exceção da E1, que pertence ao sistema de ensino e possui quadro de docentes lotados na instituição, as demais escolas não possuem quadro docente próprio. Nesta pesquisa, o que se constata nos documentos oficiais e questionários é que, na sede de qualquer das escolas, geralmente situada na capital, estão lotados profissionais "cedidos" ou convidados, tanto para os cursos centralizados como para os descentralizados. Os profissionais são remunerados por hora-aula ou como pesquisadores.

Fortes (2009), em pesquisa realizada em uma das ETSUS com foco no vínculo de 194 docentes, registrou alguns resultados, expressos a seguir: 92,5\% possuem outra vinculação no mercado de trabalho, 16,6\% lecionam em outras instituições, inclusive na universidade, e $77 \%$ possuem cursos de pós-graduação. A pesquisa registrou, ainda, queixas sobre a precariedade do vínculo e a desvalorização do trabalho, principalmente no atraso do pagamento de hora-aula. No entanto, ao aprofundar o sentido da prática docente, que trata dos imaginários e afetividades, foram encontradas respostas interessantes dos professores, tais como o alcance da realização profissional, sendo a escola o espaço representativo desse projeto/ missão, a valorização ao contexto de troca e compartilhamento, o auxílio na melhoria das práticas assistenciais, o reconhecimento por parte dos alunos e da escola e a aquisição de vínculo emocional.

A autora assinala que talvez se possa compreender que a docência, a realização profissional daí advinda e o que poderíamos chamar de "a arte de ensinar" cimentam o vínculo com a escola. Destaca, ainda, que a ETSUS, enquanto organização, simboliza o espaço de realização de uma missão importante, fazendo com que os docentes se sintam vinculados a ela. 
$\mathrm{Na}$ gestão democrática, foram encontrados no regimento de todas as escolas, os órgãos colegiados, traduzidos na forma de conselhos consultivos. Apenas a E3 possui um conselho de natureza deliberativa, organizativa e consultiva, e é também nessa escola que o diretor é eleito pela comunidade escolar - os demais são indicados pelas mantenedoras.

Ferreira (1999) comenta que o ato de participar em diversos níveis ou graus, desde a simples informação, avançando para opinião, voto, proposta de solução de problemas, acompanhamento e execução das ações é que deve gerar um sentimento de corresponsabilidade sobre as ações.

O PPP em todas as escolas foi amplamente discutido com atores internos e externos a elas, como os gestores e o pessoal técnico dos serviços de saúde. Segundo Veiga, o PPP (1995) é "um instrumento de que a escola lança mão para se propor a se lançar para frente em suas ações educativas, buscar um rumo, romper com o presente, visando ao futuro.” Ressalta ainda, que o projeto é político-pedagógico na medida em que é uma ação intencional com um compromisso definido com a formação do indivíduo para um tipo de sociedade.

$\mathrm{Na}$ dimensão pedagógica, a E2 adota uma organização modular, com itinerário formativo cujo primeiro módulo é comum a todos os cursos. Todas organizam seu currículo tendo por base o referencial das competências expressas nas Diretrizes Curriculares Nacionais. A E3 tem por opção a organização curricular diferenciada para o nível técnico e para o superior, talvez por ser uma escola de pós-graduação.

Nessa dimensão pedagógica, a E3 demonstrou de forma clara, tanto no PPP quanto no regimento, conviver com dois modelos de escola completamente distintos: a escola profissional de nível técnico e a de pós-graduação. No entanto, ela preserva a origem e as ações da escola técnica que passou a ser coordenadoria da escola de pós-graduação.

Pintarelli (2009) realizou investigação com abordagem qualitativa, com entrevista gravada, em que explora a vivência de participantes na execução do curso de Auxiliar de Saúde Bucal, realizado em 26 municípios do estado de Santa Catarina. Sobre a integração ensino-serviço foram entrevistados três sujeitos: gestores de saúde bucal, docentes assistenciais e alunos egressos. Os primeiros enfatizaram a importância da integração teoria e prática e da capacitação 
pedagógica. Entre os docentes assistenciais, confirma-se que a integração ensino-

serviço proporciona a interação entre docente e aluno, promove a aprendizagem e a integração teoria e prática. Os egressos, enfim, confirmam que a integração proporciona a interação entre docente e aluno e associação entre teoria e prática. A autora ressalta também a estratégia de integração ensino-serviço como "modo adequado de organizar as atividades didático-pedagógicas, com inúmeras vantagens em relação a outros modelos, permitindo que alunos e docentes possam desenvolver-se durante as atividades que realizam juntos [...]".

Todas as escolas se referiram à adoção de metodologias ativas, privilegiando principalmente as estratégias problematizadoras e a metodologia de projetos interdisciplinares. Também afirmaram utilizar diferentes técnicas de avaliação e expressar seu resultado por meio de conceitos. Nenhuma delas se refere à aplicação das provas convencionais.

A E1 e a E2 realizam estágio em instituições públicas, privadas e filantrópicas, desenvolvido paralelamente às aulas, e não ao final do curso. A E3 só permite estágio para o curso superior após cumprimento de $2 / 3$ da carga horária total. Para os cursos técnicos, o estágio é realizado concomitantemente ao curso e no próprio ambiente de trabalho.

$\mathrm{Na}$ questão administrativo-financeira, somente a $\mathrm{E} 3$ possui orçamento próprio e autonomia para executá-lo. Pelo questionário, pode-se verificar que todas captaram recursos externos a suas instituições, mas são unânimes em afirmar que é grande a dificuldade de execução desses recursos e dos provenientes de outras fontes. A tabela abaixo exemplifica essa colocação:

Tabela 1. Atividades administrativo-financeiras que a escola realiza, por nível de dificuldade

\begin{tabular}{lccccc}
\hline Atividades & E1 & E2 & E3 & E4 & E5 \\
\hline Contrata Serviços de Terceiros & 2 & 2 & 1 & 1 & 1 \\
Adquire Material Permanente & 2 & 2 & 1 & 1 & 1 \\
Adquire Material de Consumo & 2 & 2 & 2 & 1 & 1 \\
Realiza Pagamento de Contratos & 2 & 2 & 2 & 1 & 2 \\
\hline
\end{tabular}

1 - Não realiza 2 - Realiza com dificuldade 3 - Realiza sem dificuldade

Fonte: Questionário respondido pelas ETSUS 
Apenas a E3 tem autonomia técnico-pedagógica e administrativo-financeira e as demais, somente nos aspectos pedagógicos.

No que diz respeito à informatização dos processos administrativos, a E2 e a E4 sequer estão informatizadas. Isnal (2009) critica a falta de estrutura nas ETSUS, justificando não serem capazes de integrar-se enquanto rede e muito menos de potencializar as informaçôes. As poucas que têm sistema informatizado utilizamnos, geralmente, para atender somente a suas necessidades internas. Angeloni (2003) enfatiza a importância de um sistema de informação ao afirmar que "para a tomada de decisão com rapidez e qualidade é importante a disponibilidade de um sistema de comunicação eficiente, que permita a rápida circulação da informação e do conhecimento, sendo indispensável a tecnologia."

Para solucionar a fragilidade da dimensão administrativo-financeira, há recomendações das escolas, com exceção da E3, em aprofundar as questões da modernização gerencial e administrativa, propondo, inclusive, mudanças dos instrumentos jurídicos que as regulam.

\section{Conclusão}

A análise dos documentos forneceu elementos para compreender fortalezas e fragilidades dessas escolas criadas e "recriadas" em contextos de contradiçóes entre o desejo de uma educação integral e uma educação profissional fortemente influenciada pelo tecnicismo.

A opção pelo currículo integrado indicou a importância dada à articulação ensino-serviço. A opção unânime pelos currículos baseados em competências indica que as escolas têm por base os Referenciais Curriculares Nacionais do Conselho Nacional de Educação (RCN/CNE) e as normas sobre o desenvolvimento dos currículos por competências, exigidas pelo Banco Interamericano de Desenvolvimento ao financiar o Projeto de Profissionalização dos Trabalhadores da Área da Enfermagem, no qual toda a RETSUS participou de forma efetiva.

Ao serem estabelecidos esses referenciais, as escolas se sentiram, por um lado, obrigadas a assumir os currículos baseados em competências e, por outro, "inseguras", pois não estavam "preparadas" para a sua implantação. A discussão das bases de um currículo fundamentado em competências ainda é superficial, razão pela qual as escolas adotaram, na íntegra e de forma pouco crítica, os 
RCN. Isso dificulta a elaboração e a incorporação de referenciais conceituais que propiciem a compreensão de currículos organizados dessa forma. Acredita-se que isso ainda é muito presente na maior parte das escolas do sistema de ensino ou nas escolas setoriais, como no caso das ETSUS, pelo próprio caráter polissêmico do ensino baseado em competências.

Todas as escolas se referiram à adoção de metodologias ativas. A problematização encontra nas ideias de Paulo Freire um sentido de inserção crítica na realidade, para dela retirar os elementos que conferirão significado e direção às aprendizagens. No movimento ação-reflexão-ação são elaborados os conhecimentos, considerando a rede de determinantes contextuais, as implicações pessoais e as interações entre os diferentes sujeitos que aprendem e ensinam (FREIRE, 1987).

O eixo metodológico que busca integrar o ensino ao serviço é registrado por quatro das cinco escolas. Para Barzenski (2009), a metodologia de integração ensino-serviço propõe que se articulem teoria e prática de forma a aprimorar o pensar e o agir e melhorar a qualidade do trabalho, e que os cursos na área da saúde tenham seus conteúdos integrados à prática, prevendo questóes que vão desde os temas específicos de cada função profissional até as relações humanas, perpassando situações éticas.

No Brasil, a discussão sobre a articulação ensino-serviço de saúde no processo de formação, tanto para graduação como para o ensino técnico, vem apresentando ao longo das últimas décadas propostas bem ou mal sucedidas, com avanços e retrocessos de experimentação dessa estratégia, que vem, todavia, sendo enfatizada como uma das principais para a formação de um profissional mais adequado às necessidades de saúde do país, segundo Pinto, Formigli e Rêgo (2007).

Esses autores salientam como dificuldades da integração ensino-serviço, dentre outras: o planejamento conjunto envolvendo escola e serviços de saúde; o planejamento da docência; a falta de entendimento do que é a proposta de integração; a falta de domínio pelos profissionais de saúde do modelo assistencial e das rotinas de trabalho; a falta de estrutura física e de equipamentos nos espaços dos cursos descentralizados; e a falta de sensibilização dos gestores, que dificulta a liberação dos servidores para momentos específicos da formação. Por outro lado, apontam como facilidades: a abertura dos espaços dos serviços para os processos educativos; a abertura dos profissionais em receber os alunos trabalhadores com suas diferentes experiências; a realidade da oferta concreta dos serviços à população; 
a existência de uma política pública para a formação e de uma base legal que a sustente; a colaboração entre alunos trabalhadores e profissionais docentes; e a participação das ETSUS na discussão, elaboração e execução dos cursos.

A integração ensino-serviço nas ETSUS é uma experiência ímpar e em construção, e os gestores reconhecem que ela faz a diferença, tanto na compreensão dos problemas envolvendo o contexto, como nas soluções que contribuem para organizar os serviços de saúde. Além disso, essa metodologia favorece a integração do conhecimento e sua aplicação na prática, buscando romper com a fragmentação disciplinar, conforme afirma Morin (2000): "A supremacia do conhecimento fragmentado de acordo com as disciplinas impede [de] operar o vínculo entre as partes e a totalidade, impossibilitando apreender os objetos em seu contexto e sua complexidade [...]."

Outro aspecto da dimensão pedagógica apontado pelas escolas é a aprendizagem significativa, que, segundo Pelizzari e colaboradores (2002, p. 37), "propóe que os conhecimentos prévios [...] sejam valorizados, para [...] construir estruturas mentais utilizando, como meio, mapas conceituais que permitem descobrir e redescobrir outros conhecimentos [...] construindo uma aprendizagem prazerosa e eficaz".

Sendo a proposta pedagógica das escolas baseada em teorias e práticas emancipadoras, a avaliação expressa no PPP e no Regimento Escolar procurou seguir os mesmos fundamentos, caminhando de mãos dadas com o processo ensino-aprendizagem, num eterno movimento de integração.

As dificuldades apresentadas pelas cinco escolas na dimensão pedagógica estão relacionadas ao acompanhamento das turmas descentralizadas, uma vez que não há um amplo quadro de profissionais cedidos às escolas, nem dados sistematizados sobre docentes e cursos. Há também dificuldades relacionadas a um maior aprofundamento do conceito de integração ensino-serviço por parte dos instrutores-supervisores, bem como à rotatividade e outros vínculos dos docentes e à carência de material didático, principalmente de livros-textos para o ensino técnico. Como facilidades encontradas pelas escolas, foram percebidos o compromisso da equipe das instituições, o domínio que possuem os profissionais em sua área de atuação, a facilidade dos campos de estágio, a utilização de metodologias ativas, o comprometimento do corpo docente, a realização das capacitações pedagógicas e o processo de descentralização. 
Como visto anteriormente, somente a E3 possui orçamento próprio. As demais escolas, sem orçamento próprio proveniente do tesouro do Estado, ressaltaram a importância do financiamento assegurado pelo Ministério da Saúde para a execução da política de educação profissional e demonstraram capacidade de captação de recursos em outras fontes. Assinalam, ainda, que, por meio da Política Nacional de Educação Permanente (PNEPS), também financiada pelo ministério, foram capazes de tomar assento e apresentar projetos de formação/qualificação na área técnica nas instâncias que fomentam ou viabilizam essa política.

Como facilidades na dimensão administrativo-financeira, as escolas apontaram, dentre outras, os repasses do Ministério da Saúde, mesmo com todas as dificuldades de execução; a viabilidade para a execução dos cursos devido ao apoio oferecido pelas Secretarias Municipais de Saúde e pelos próprios serviços; os profissionais administrativos capacitados; o comprometimento da gestão e dos funcionários na resolução dos problemas na área.

Borges e colaboradores (2012) publicaram um estudo sobre a sustentabilidade administrativa das ETSUS a partir do princípio da integração ensino-serviço, que traz uma nova dimensão do trabalho na saúde, e ainda não regulada pela administração pública brasileira. O universo amostral foi de seis ETSUS, em sua maioria sem autonomia administrativa e altamente dependentes de financiamento do governo federal. Segundo os gestores das escolas, a falta de regulação da atividade docente para o servidor público fragiliza a gestão das ETSUS. Essas instituições apresentam problemas de gestão relacionados à integração ensinoserviço, principalmente quanto ao pagamento de hora-aula, que precisa ser regulamentado para conferir sustentabilidade às escolas e evitar contradiçôes com a legislação brasileira.

Quanto à importância de se ter um sistema de informação adequado, a escola deve ser capaz de obter as informações de forma rápida, segura e fácil. Nesse sentido, a existência de um sistema informatizado como uma ferramenta de suporte para o sistema de informação poderia facilitar consideravelmente a organização, armazenamento, recuperação, correlação de dados e elaboração de relatórios. Davenport (2000, p.58) corrobora essa pressuposição ao afirmar que "a tecnologia disponível no mercado, bem como as tecnologias específicas que cada empresa decide implementar, com certeza, pode afetar o tipo de informação disponível e a facilidade em acessá-la [...] “ 
Ainda nos aspectos administrativo-financeiros, as cinco escolas levantaram como dificuldades a falta de um sistema de monitoramento das ações, a falta de capacitações específicas para os profissionais da área meio, a dificuldade em pagar hora-aula aos servidores, a falta de veículos para a supervisão dos cursos descentralizados, o atraso na aquisição de materiais e no repasse das parcelas e, em especial, a falta de autonomia para a execução das ações nessa área.

Uma das dificuldades pontuadas é o desconhecimento por parte das mantenedoras, das atividades que a escola desenvolve. Isso dificulta o diálogo, a liberação dos recursos e o atraso nos repasses. Outra questão apontada é a necessidade de apropriação por parte dos gestores do que é a educação profissional e da ETSUS como seu espaço permanente. Essa dificuldade de compreensão reforça a resistência na liberação dos funcionários, por fatores diversos, para a realização dos cursos.

Enquanto processo político que são, algumas escolas da RETSUS ganharam força à medida que aumentou o compromisso do gestor com a saúde pública e o entendimento de que uma assistência de qualidade passa necessariamente por uma melhor formação dos trabalhadores que ali atuam. Nesse mesmo sentido, a luta pela profissionalização dos trabalhadores da saúde é também a luta por um projeto político da sociedade.

Os objetivos propostos de explorar as visões político-pedagógicas dos documentos e respostas ao questionário e a forma que as escolas se organizam e se estruturam com vistas à sua sustentabilidade foram satisfatoriamente alcançados.

A dimensão política, de acordo com os dados da pesquisa, foi a que mais se sobressaiu, tendo em vista o nível de articulação dessas instituições com os poderes decisórios que fortalecem e validam suas açōes, como a Comissão Intergestora Bipartite, os Colegiados de Gestão, as Comissões de Integração Ensino-Serviço das Secretarias Estaduais e Municipais de Saúde. A descentralização - enquanto possibilidade de inclusão dos trabalhadores dos municípios nos processos de formação/qualificação - consolidou a oportunidade de acesso e permanência dos alunos-trabalhadores em processos educativos.

A área técnico-pedagógica, que contempla a identidade da escola e o poder decisório referente à melhoria do processo ensino-aprendizagem para garantir o alcance da missão, mostrou-se a mais estruturada, com ampla autonomia. 
Algumas dessas escolas realizaram, inclusive, experiências inovadoras, como a

E3, que oferta cursos semipresenciais e é sede de um Observatório de Recursos Humanos para o nível técnico em saúde.

A dimensão pedagógica, com sua proposta de PPP inovador, é efetivamente a que mais dá sustentabilidade às ETSUS, tornando-as diferentes das escolas do sistema formal de ensino pela incorporação de princípios de gestão à descentralização curricular, processos administrativos centralizados e atuação multiprofissional no campo da saúde. Sua fortaleza pedagógica é traduzida principalmente pela existência do eixo metodológico de integração ensino-serviço, adequação do currículo ao contexto regional, utilização pedagógica dos espaços de trabalho, avaliação do desempenho dos alunos nos serviços com supervisão e acompanhamento pedagógico e docência exercida no campo de trabalho por profissional de nível superior qualificado pedagogicamente tendo os princípios e diretrizes do SUS como norteadores dos planos de cursos.

Mesmo sendo a dimensão pedagógica a que indica estar mais estruturada, as escolas 1 e 4 sugerem estudos que aprofundem principalmente a integração ensino-serviço e o trabalho como princípio pedagógico. Ramos (2010), em recente estudo sobre as ETSUS, também sugere aprofundamento nesses aspectos. As escolas indicaram ainda outros temas que julgam importantes de serem estudados em outras pesquisas, como o trabalho como princípio pedagógico, o espaço de trabalho como um locus de aprendizagem, a função docente e suas bases filosófico-pedagógicas em modelos de escolas como as ETSUS e a regulamentação que permite ao profissional da saúde ser remunerado pela função docente.

A dimensão administrativo-financeira foi apontada como o maior desafio a superar. As escolas foram unânimes em afirmar que é grande a dificuldade de executar recursos do orçamento provenientes de todas as fontes. No entanto, nenhuma delas deixa de executar seu planejamento, seja utilizando instituições com autonomia financeira para gerir os recursos, seja "encarando" os trâmites das secretarias de saúde. Nesse último caso, o processo é mais lento e exige um acompanhamento muito próximo às instâncias de execução.

Embora haja fontes de financiamento, os problemas apresentados no questionário apontaram para a escassez dos recursos frente às demandas do SUS, a falta de autonomia, a dificuldade de execução dos recursos, seja pelo 
atraso ou por entraves burocráticos, a falta de capacitação específica para a área, a dificuldade em pagar hora-aula aos servidores públicos e para o atraso no repasse das parcelas dos recursos provenientes do tesouro do Estado ou do Ministério da Saúde. Sousa e Hamann (2009) afirmam que, no tocante aos recursos financeiros, é imperativo que os gestores do SUS enfrentem o desafio na definição de novos mecanismos de financiamento que contribuam para a redução das desigualdades regionais e para uma melhor proporcionalidade entre os três níveis de atenção do SUS.

A escolha de escolas de mantenedoras diferenciadas partiu do pressuposto de que os aspectos de sustentabilidade nas dimensões pretendidas poderiam apresentar disparidades. Isso não foi constatado nesse estudo, pois todas apresentaram, de modo geral, as mesmas facilidades e dificuldades. Assim, a mantenedora não é determinante na sustentabilidade das escolas.

A escolha de uma escola por região deu-se apenas para que se tivesse uma "visão" das semelhanças e diferenças entre escolas, o que também não teve resultados expressivos dignos de registro. Isso indica que a ETSUS, idealizada por Izabel dos Santos e colaboradores, vem conseguindo consolidar-se de maneira a assegurar uma unidade filosófica, política, pedagógica e administrativa, sem ser, contudo, uniforme. Vale lembrar que a ETSUS antecedeu a LDB em quase vinte anos nos aspectos inerentes à educação profissional.

Um dos grandes ganhos promovidos pelas ETSUS foi o fortalecimento da qualidade pedagógica e a preocupação com a titulação de validade nacional daqueles já inseridos na área da saúde. Rompe-se, assim, a ideia de que, para qualificar os trabalhadores, bastariam os serviços por si sós, com a transferência de experiência entre eles ou por meio de meros treinamentos. Esse ganho eleva a ETSUS à condição de protagonista do resgate de uma parcela da dívida social: educação inclusiva, pública, com oportunidade de acesso e permanência aos trabalhadores empregados no SUS. ${ }^{1}$

\section{Referências}

ANGELONI, M.T. Elementos intervenientes na tomada de decisão. Ci.Inf. Brasília, v. 32, n. 1, p. 17-22, jan-fev 2003.

BARDIN, L. Análise de conteúdo. Lisboa: Edições 70, 2007. 
BARZENSKI, A. A integração ensino-serviço no desenvolvimento das competências do agente comunitário de saúde: da sala de aula ao dia a dia de seu trabalho. 2009. Dissertação (Mestrado em Saúde Pública) - Escola Nacional de Saúde Pública Sérgio Arouca, Fundação Oswaldo Cruz, Rio de Janeiro, 2009.

BORGES, F.T. et al. Escolas Técnicas do SUS (ETSUS) no Brasil: regulação da integração ensino-serviço e sustentabilidade administrativa. Ciência e Saúde Coletiva, v. 17, n. 4, p. 977-987, 2012.

BRASIL. Ministério da Saúde. Portaria no 2 970, de 25 de novembro de 2009. Institui a Rede de Escolas Técnicas do SUS (RETSUS) e dispõe sobre as diretrizes para a sua organização. Diário Oficial da União, Brasília, 2009.

CERQUEIRA, A.S. O desenvolvimento profissional dos professores da educação superior privada: um devir em movimento. Tese (Doutorado) - Universidade de Brasília, Brasília, 2011.

DAVENPORT, T.H. Ecologia da informação: porque só a tecnologia não basta para o sucesso na era da informação. São Paulo: Futura, 2000.

FERREIRA, R. (Coord). Construindo a educação na cidade de Camaragibe. Camaragibe: Secretaria da Educação, 1999.

FORTES, D.R. Precarização do vínculo empregatício e suas implicações subjetivas para os docentes da Escola Técnica de Saúde "Profa Ena de Araújo Galvão". Dissertação (Mestrado em Saúde Pública) - Escola Nacional de Saúde Pública Sérgio Arouca, Fundação Oswaldo Cruz, Rio de Janeiro, 2009.

FREIRE, P. Pedagogia do oprimido. Rio de Janeiro: Paz e Terra, 1987.

ISNAL, A. Necessidades de Informação para as Escolas Técnicas do SUS. Dissertação (Mestrado em Saúde Pública) - Escola Nacional de Saúde Pública Sérgio Arouca, Fundação Oswaldo Cruz, Rio de Janeiro, 2009.

LEÃO, L.M.P. A prática pedagógica nos cursos de Educação Profissional Técnica de Nível Médio em Saúde: a percepção do professor. Dissertação (Mestrado em Saúde Pública) - Escola Nacional de Saúde Pública Sérgio Arouca, Fundação Oswaldo Cruz, Rio de Janeiro, 2009. MACHADO, M.H. Trabalhadores da saúde e sua trajetória na Reforma Sanitária. Cadernos RH Saúde. Brasília, v. 3, n. 1, p. 13-27, 2006.

MORIN, E. Os sete saberes necessário à educação do futuro. São Paulo: Cortez, 2000.

NOGUEIRA, R.P. A força de trabalho em saúde. Revista de Administração Pública, Rio de Janeiro., v. 17, n. 3, jul-set 1983.

PELIZZARI, A. et al. Teoria da aprendizagem significativa segundo Ausubel. Revista PEC, Curitiba, v. 2, n. 1, p. 37-42, jul. 2002.

PEREIRA, I.B.; RAMOS, M. Educação profissional em saúde. Rio de Janeiro: Fiocruz, 2006. 
PINTARELLI, K.L.B. Avaliação da integração ensino serviço no curso de auxiliar em saúde bucal. Dissertação (Mestrado) - Programa de Pós-graduação em Saúde e Gestão do Trabalho, Itajaí, 2009.

PINTO, L.L.S.; FORMIGLI, V.L.A.; RÊGO, R.C.F. A dor e a delícia de aprender com o SUS: integração ensino-serviço na percepção dos internos em medicina social. Revista Baiana de Saúde Pública. Salvador, v. 31, n.1, jan-jun, 2007.

RAMOS, M. Trabalho, educação e correntes pedagógicas no Brasil: um estudo a partir da formação dos trabalhadores técnicos da saúde. Rio de Janeiro: EPSJV, 2010.

RODRIGUES, T.M. Políticas de educação profissional em saúde. Projeto Larga Escala e Educação Permanente: uma análise comparativa. Dissertação (Mestrado) - Programa de Pós-graduação em Saúde e Gestão do Trabalho, Itajaí, 2009.

SÓRIO, R.; LAMARCA, I. Novos desafios das Escolas Técnicas de Saúde do SUS. PhysisRevista de Saúde Coletiva. Rio de Janeiro, v. 8, n. 2, p. 147-164, 1998.

SOUSA, M.F.; HAMANN, E.M. Saúde da Família no Brasil: estratégia de superação da desigualdade social? Physis-Revista de Saúde Coletiva. Rio de Janeiro, v. 19, n. 3, p. 711-729, 2009.

VEIGA, I.P.A. Inovações e projeto político-pedagógico: uma relação regulatória ou emancipatória? Cad. Cedes, Campinas, v. 23, n. 61, p. 267-281, dez 1995.

\section{Nota}

${ }^{1}$ E.A. Galvão participou da coleta e análise de dados, da discussão dos resultados e da redação final do artigo. M.F. Sousa participou da análise e discussão dos resultados e da revisão teórica do artigo. 


\section{Technical Health Schools: which political and pedagogical projects support them?}

This paper aimed to explore the political and pedagogical views expressed by managers of five Technical Schools from the Brazilian Unified Health System (ETSUS), in five regions of Brazil. It also focused on understanding how these institutions organize and structure themselves towards their sustainability. The method searched for qualitative aspects. Data were collected from a questionnaire through the internet, and documents such as: certification of establishment, authorization, Political Pedagogical Project (PPP) and school regulations. The semi-structured questionnaire was directed to the participating institutions, to identify their sustainability within the administrative and finance, technical pedagogical and political dimensions. The technique used to organize and store data and content analysis was the document analysis, according to the methodology proposed by Bardin (2007). Results show that there had been fluctuations in the different dimensions, mainly in the finance administrative fields where the managers' governance was rather fragile. Other results pointed that the technical and pedagogical dimension, with its innovative PPP proposal, is the one that gives more sustainability to ETSUS, making them different from the formal educational system, through the incorporation of management principles to the decentralized curricula, centralized administrative processes and multi-professional acting in the field of health. Its pedagogical strength is mainly translated by the existence of the methodological axis on teaching in service integration, suitability of the curriculum to the regional context, pedagogical use of the working spaces, performance evaluation of the students under services with supervision and pedagogical follow-up, teaching in the work field by a pedagogically qualified professional having the guidelines and principles of the SUS as directions for the course plans. The political dimension was the one which provided more visibility to the school work, also capable of favoring more sustainability. The education/qualification in the municipalities has brought benefits to students/workers and allowed a closer performance to the decentralized areas of management and decision. In the conclusions, the difficulties encountered by the schools were analyzed where there is also the need to correct asymmetries in the technical pedagogical and administrative and finance dimensions.

Key words: Technical Schools of the Unified Health System; political pedagogical project; vocational education; sustainability. 